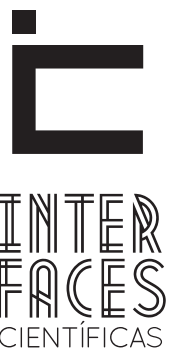

EDUCAÇÃO

\title{
GRAMÁTICA, INTERAÇÃO E ENSINO DE LÍNGUA MATERNA: PROCEDIMENTOS DISCURSIVOS NA FALA E NA ESCRITA DE ITABAIANA/SE
}

\author{
Raquel Meister Ko. Freitag \\ Eccia Alécia Barreto ${ }^{3}$ \\ Heloísa Cristina Renovato ${ }^{5}$
}

\section{RESUMO}

Neste trabalho, objetivamos identificar e descrever procedimentos discursivos da fala e da escrita, relacionados às estratégias de interação, sequenciação de informações e de evidencialidade/modalização. A análise toma como corpus duas amostras: uma de fala e outra de escrita. Os resultados apontam para a sistematicidade entre usos linguísticos e contextos sociais, contribuindo para elaboração de materiais didáticos que contemplem a diversidade e a variedade linguística.

\section{PALAVRAS-CHAVE}

Usos Linguísticos. Procedimentos Discursivos. Ensino.

\author{
Andréia Silva Araujo \\ Jackeline de Carvalho Peixoto \\ Thiers de Andrade Soares ${ }^{6}$
}

\section{ABSTRACT}

In this paper we focuses identify and describe discursive procedures in speech and writing based on interaction strategies, sequencing if information and evidentiality/modalization. The corpus analysis is composed of two samples - one of speech and other writing. The results point that language usage and social contexts are systematic, corroborating to production of didactics materials which focus linguistics diversity and variety.

\section{KEYWORDS}

Language Usage. Discursive Procedures. Teaching. 


\section{RESUMEN}

El objetivo del estudio es identificar y describir los procedimientos discursivos del habla y de la escritura en relación a estrategias de interacción, secuenciación de informaciones y evidencialidad / modalización. El análisis toma como corpus dos muestras: una de habla y otra de escritura. Los resultados apuntan que hay una relación sistemática entre los usos lingüísticos y los contextos sociales, contribuyendo para la elaboración de materiales didácticos que privilegien la diversidad y la variedad lingüística.

\section{PALABRAS CLAVE}

Usos lingüísticos. Procedimientos discursivos. Enseñanza.

\section{INTRODUÇãO'}

Procedimentos discursivos é o conjunto de processos interacionais atuantes no planejamento e na verbalização da situação comunicativa. Além das peculiaridades regionais, pressões de ordem pragmática podem se sobrepor às exigências da sintaxe, fazendo com que as estruturas sejam adaptadas ao contexto. Interessam para esta investigação os procedimentos discursivos concebidos como resultado de ações pragmaticamente controladas, que podem ser enquadrados em uma trajetória de gramaticalização. A gramaticalização é o processo de emergência e regularização das formas linguísticas na sua trajetória do discurso para a sintaxe (HOPPER; TRAUGOTT, 1993; HEINE et al., 1991). Permeando a mudança, estão pressões sociais (analisadas sob a perspectiva da Sociolinguística Variacionista), as quais atuam direcionando a mudança linguística (FREITAG, 2008).

Por se tratar de formar emergentes, os procedimentos discursivos existem na gramática internalizada do falante, mas não como categoria na gramática normativa. Por conta disso, são frequentemente alvo de estigma social. Uma das características da compe-

10 projeto "Procedimentos discursivos na fala e na escrita de Itabaiana/SE" foi financiado pela Fundação de Apoio à Pesquisa e à Inovação Tecnológica do Estado de Sergipe - FAPITEC/SE (edital 03/2007 Universal), além de participar do Programa Institucional de Iniciação Científica UFS/CNPq 2008/2009. tência sociodiscursiva do falante é o uso de procedimentos discursivos adequadamente em sua fala, pois não são meros "preenchedores de vazios" da comunicação, mas sim estratégias elaboradas de avaliação do conteúdo proposicional, retomada e manutenção de turno, foco de atenção e de coesão textual, sendo necessário incluí-los nos programa de ensino de língua materna, alinhando-se às diretrizes norteadoras dos Parâmetros Curriculares Nacionais (BRASIL, 1998), que são articulados em torno do eixo uso - reflexão.

Procedimentos discursivos resultados de processo de gramaticalização são itens linguísticos variáveis, sensíveis aos contextos sociocultural e regional, fazendo com que seja necessário realizar um levantamento em cada localidade, a fim de contribuir plenamente, não só com a descrição do português falado no Brasil, mas, também, suprir uma carência de estudos localizados para subsidiar a elaboração dos projetos pedagógicos de ensino de língua materna. A fim de contribuir para esta ação maior, o objetivo deste trabalho é apresentar os resultados de uma investigação, focados em procedimentos discursivos na fala e na escrita de Itabaiana/SE, de modo a identificar os itens linguísticos mais recorrentes no desempenho de funções de evidencialidade/modalização, interação e sequenciação, sua trajetória de mudança linguística e seu traço indicativo sociocultural. 


\section{PROCEDIMENTOS DISCURSIVOS}

Focamos três tipos de procedimentos discursivos: as estratégias de interação, sequenciação de informações e evidencialidade/modalização.

\subsection{ESTRATÉGIAS DE INTERAÇÃO}

Estratégias de interação referem-se a caminhos de que se valeu o escritor/falante para melhor se aproximar de seu leitor/ouvinte e conseguir atingir os objetivos a que se propõe. Os procedimentos discursivos interacionais são caracterizados por desempenhar funções relacionadas à organização da fala no plano interpessoal, dada a sua origem como pergunta; e interpessoal e textual, como elementos focalizadores de informações no texto. Foca-se essa análise nas perguntas, especificamente na escrita. Na fala, perguntas são construções linguísticas que se realizam por meio de uma sintaxe interrogativa, entonação ascendente que permite identificar sua função.

\subsection{ESTRATÉGIAS DE SEQUENCIAÇ̃̃O DE INFORMAÇ̃̃ES}

O caráter de "tessitura" de um texto é conferido dado o uso de recursos coesivos, pois "[...] a coesão como fenômeno diz respeito ao modo como os elementos linguísticos presentes na superfície textual se encontram interligados entre si, por meio de recursos linguísticos, formando sequências veiculadoras de sentido" (KOCH, 2008, p. 45). Dentre esses recursos estão os conectores sequenciadores, que funcionam como articuladores textuais; pode-se considerá-los como variantes do domínio funcional de sequenciadores de informação.

Uma das funções dos conectores sequenciadores é a de gerar, com certa ligação coesiva, a articulação dos segmentos de um texto, seja na organização dos tópicos ou na estrutura frástica, já que, para se ter um
O uso de perguntas está constantemente presente na língua falada com o intuito de causar uma maior proximidade entre os interlocutores, configurando uma estratégia de interação para o desenvolvimento da comunicação. 0 que motiva o uso de perguntas no texto escrito, na medida em que não há um interlocutor síncrono para respondê-la? Embora aparentemente "não faça sentido", constata-se um uso produtivo de perguntas como estratégia de interação na escrita. Na seção 4 explicitar-se-ão as funções identificadas na amostra.

texto coeso, é essencial atentar ao modo como se trabalha a progressão temática, o que contribui com o uso dos conectores sequenciadores.

Aí, daí, depois, então, e, portanto são os conectores sequenciadores mais recorrentes no português falado do Brasil (TAVARES, 2003), no entanto, no que diz respeito à escrita, nem todos esses conectores são recorrentes. Os empregos não adverbiais de conectores daí e aí costumam ser considerados vícios de linguagem pelos professores de Língua Portuguesa e, por isso, são estigmatizados socialmente e, devido a isso, talvez não sejam encontrados com tanta frequência na escrita. Já sequenciadores como e, então, portanto, etc., que não são estigmatizados, devem ser mais facilmente encontrados em textos escritos. Para 
dar conta destas hipóteses acerca da distribuição dos conectores sequenciadores, será apresentada uma análise quantitativa variacionista na seção 4.

\subsection{ESTRATÉGIAS DE EVIDENCIALIDADE/MODALIZAÇÃO}

Marcadores evidenciais indicam algo sobre a fonte de informação de uma proposição (BYBEE; PERKINGS; PAGLIUCA, 1994). A categoria linguística da evidencialidade envolve outros domínios do conhecimento, relacionado à modalidade epistêmica, como as crenças e os julgamentos, não sendo possível dissocia-las; por isso, optou-se por designar de estratégias de evidencialidade/modalização os recursos linguísticos relacionados à expressão do distanciamento e a origem da informação em relação ao falante.

\section{METODOLOGIA}

Por se tratar de uma proposta de investigação da língua em uso, constituímos um corpus composto por duas amostras: a amostra Entrevistas sociolinguísticas, composta por 12 informantes estratificados quanto ao sexo, escolaridade e faixa etária, cuja coleta seguiu a metodologia da Sociolinguística Variacionista (WEINREICH; LABOV; HERZOG, 2006; LABOV, 2008); e a amostra Fala\&Escrita, constituída aos moldes do projeto Discurso\&Gramática (FURTADO DA CUNHA, 2000), com 10 informantes, que produziram cinco tipos distintos de textos orais e, a partir destes,
Diferentemente das estratégias de interação e de sequenciação, as estratégias de evidencialidade/modalização, no português, não são ainda entendidas como regulares, mas há estudos que sugerem que há certas construções em vias de gramaticalização (FREITAG, 2003). Na seção 4, será apresentada uma análise da gramaticalização das construções que marcam evidencialidade/modalização na fala e na escrita de Itabaiana/SE.

cinco textos escritos, para assim garantir a comparabilidade entre a modalidade falada e escrita, totalizando 100 registros, além de 80 redações de alunos do $6^{\circ}$ e do $9^{\circ}$ ano, de caráter narrativo e dissertativo.

Os tipos de textos são: narrativa de experiência pessoal, narrativa recontada, descrição de local, relato de procedimento e relato de opinião. As amostras orais foram transcritas segundo normas próprias de transcrição; a edição dos textos escritos preservou os aspectos ortográficos originais.

\section{RESULTADOS}

A perspectiva teórica adotada para a análise reúne pressupostos da teoria variacionista laboviana e da teoria funcionalista de linha norte-americana, segundo a qual a gramática, motivada e explicada pela situação comunicativa,

é estruturante de aspectos comunicativos da linguagem (a estrutura é vista como maleável e dependente da função), englobando, além da fonologia, morfossintaxe e semântica, também, aspectos pragmáticos inferenciais (GIVÓN, 1995). 


\subsection{PERGUNTAS COMO ESTRATÉGIAS DE INTERAÇ̃̃O NA ESCRITA}

Na fala, perguntas são construções linguísticas que se realizam por meio de uma sintaxe interrogativa, com entonação ascendente, o que nos permite identificá-las. Alguns autores têm tratado deste tema na modalidade de língua falada, como é o caso de Urbano, Fávero, Andrade e Aquino (2002), que o abordam em uma perspectiva dialógica - pergunta e resposta $(P-R)$ - evidenciando sua natureza, estrutura e função.

Já na escrita, as perguntas são associadas a um sinal de pontuação específico - a interrogação (?). Na escrita, o uso de estratégias interacionais, como convites, perguntas, repetições, solicitações, etc., propicia aproximação entre interlocutores, mantendo-os envolvidos na situação comunicativa. Tais estratégias contribuem para a construção de envolvimento na escrita, já que permitem a interação entre escritor e leitor.

Nesta análise, foram considerados 67 contextos de ocorrências de perguntas presentes na modalidade de língua escrita de Itabaiana/SE. As perguntas, dependendo da forma como são estruturadas, podem ser classificas em: plenas; retóricas e semirretóricas. Perguntas plenas são aquelas que pedem do interlocutor uma resposta ou uma confirmação do que foi dito anteriormente (um indivíduo pergunta e outro responde). Dada sua caracterização, seu uso seria pouco provável na modalidade de língua escrita. Entretanto, foram encontrados 24 casos no corpus, em redações narrativas de estudantes do $6^{\circ}$ ano; vejamos (1).

(1) Mentindo Para a Minha Mãe

Todas vezes eu saia de casa para ir a escola me batia uma preguiça. Eu ia para a lanHouse saia de casa as seis e meia e chegava meia noite ele perguntava:

estudou meu filho Sim mãe estudei quando ela perguntava se tinha deve eu dizia que não tinha eu fiquei gaseano durante um mês de aluno ela desconfiou e $m$ e transferiu para tarde e ainda em vez em quando eu gaseio nossa quem mentira grande eu fiz para a minha mãe. (Texto 5)².

No excerto (1), vemos uma pergunta e, logo após, uma resposta que, como aponta o contexto, não é dada pela mesma pessoa que efetuou a pergunta; trata-se de uma pergunta plena, que na escrita é usada em discurso reportado.

As perguntas retóricas caracterizam-se como aquelas "que não pedem a resposta do ouvinte"; são aquelas que

ocorrem quando o falante elabora uma P[ergunta]
com o intuito de que o ouvinte não responda, porque
aquele já conhece a R[esposta] e é só uma questão de
procurá-la na memória. Verifica-se que esse tipo de
P[ergunta] é usado como recurso, entre outros, para
manter o turno ou para estabelecer contato (FÁVERO;
ANDRADE; AQUINO, 2002, p. 161).

No corpus, só encontramos 2 ocorrências desse tipo de pergunta, em uma redação dissertativa, como podemos observar em (2).

(2) As pessoas vão para hospitais chegam lar reclamam que está cheio não são bem atendidos mas será que em casa ela fez a sua parte para o mosquito não se proliferar e se fez a sua vizinha fez ou não, é isso que eu tô querendo mostrar que as pessoas só pensam em reclamar e estão de lados seus cuidados para derrotar o mosquito [...] (Texto 74 ).

Em (2) são identificadas perguntas (apesar de não terem o sinal ortográfico de interrogação), às quais não há resposta de fato. Diferentemente da pergunta plena (que "exige" respostas), estas perguntas foram formuladas para não serem respondidas, já que o locutor formula a si mesmo; sua função é a de conduzir apropriadamente o leitor em direção à argumentação do escritor, caracterizando-se, assim, como uma per-

2 Como norma do banco de dados Fala\&Escrita, a ortografia e sintaxe do texto original do indivíduo foram preservadas no processo de digitalização do corpus. 
gunta retórica. Este tipo de pergunta é elaborado com fins essencialmente argumentativos, e consiste em interpelar o interlocutor a aderir ao que se anuncia. Segundo Silva (2004, p. 791), as perguntas retóricas "são muito comuns no discurso de sala de aula, utilizadas, normalmente, para manter o turno do professor ou para estabelecer contato ou para chamar atenção dos alunos"; portanto, pode ocorrer o mesmo na escrita.

No excerto (3), há a ocorrência de uma pergunta que é respondida no próprio texto; a este tipo de pergunta chama-se de semirretóricas, cuja função, assim como a das perguntas retóricas, é a de conduzir o leitor em direção à sua argumentação. No corpus em análise, foram encontradas 41 ocorrências deste tipo de pergunta.

(3) A dengue é um problema grave e que pode atingir a qualquer um de nós. 0 mosquito transmissor não escolhe a quem vai picar, não seleciona por classe social, cor ou qualquer outro critério.

A situação é emergencial, e de quem é a culpa dessa gravidade?Nossa, de todos sem excessões. Todos devemos nos preocupar e combater essa epidemia que cada vez mais vai se alastrando pelo nosso estado por vários lugares do Brasil [...] (Texto 36).

Por serem as mais produtivas na escrita, observou-se o contexto em que ocorrem as perguntas semirretóricas, identificando características que possibilitam a definição de duas categorias: perguntas semirretóricas declarativas/objetivas e perguntas semirretóricas condicionais/subjetivas. Eis um exemplo do corpus em análise de cada tipo, em (4) e (5), respectivamente:

(4) Que a dengue se espalha cada vez mais, não é novidade. Uma epidemia que atinge grande parte do país e que veio estragar a vida de muita gente, muita vezes para sempre. Mas de quem será a culpa?

Todos nós seres humanos temos o costume de sempre culpar os outros por tudo que acontece, muitas por não ter outra saída, ou mesmo para aliviar o peso da consciência. Mas a verdade e que dessa vez, a culpa por essa epidemia e de todos nós. Não nos previnimos suficiente e nem nos preocupamos o necessário. Não damos a devida importância à essa doença, até acontecer um tragédia na nossa família. Então despertamos para realidade, muitas vezes tarde de mais [...] (Texto 35)

(5) As autoridades do nosso Pais sabem que milhares de pessoas morem todos os dias. Por causa da dengue mais o que eles fazem?

Nada dizem que vão fazer campanhas contra a dengue mais isso só acontece no verão, por exemplo mais se a campanha so e feita no verão e depois o que eles fazem, nem se preocupam o depois eles acham que previnindo hoje amanhã não precisamos combater a dengue mais ela desaparece [...] (Texto 40).

As perguntas destacadas não possuem a mesma estrutura: a principal diferença entre essas duas perguntas é: em (4), o uso do verbo "ser" no futuro do presente do indicativo e a conjunção subordinativa condicional "se", os quais manifestam dúvida ou incerteza. Este tipo de pergunta ocorre de forma indireta, o que evidencia um menor comprometimento do indivíduo (locutor/escritor), já que o uso do verbo será não demonstra uma aderência ao posicionamento, manifestando dúvida, tendo, dessa forma, um caráter mais subjetivo.

Já em (5), a pergunta - mais [sic] o que eles fazem? - manifesta mais certeza (portanto, mais objetiva) por parte do locutor/escritor, demonstrando maior adesão aos seus argumentos e maior comprometimento. As perguntas semirretóricas do tipo de (4) podem ser abertas ou fechadas; já a do tipo de (5) podem ser somente do tipo aberta. Ambos os tipos de pergunta podem ser estruturadas com a presença ou não da preposição antes do pronome interrogativo. Após a análise dos contextos de uso de perguntas no corpus em análise, sumariz-se seus traços característicos no quadro 1. 
Quadro 1 - Traços característicos da ocorrência de perguntas na escrita

\begin{tabular}{l|l}
\hline \multicolumn{1}{c|}{ Tipos de perguntas } & \multicolumn{1}{c}{ Características } \\
\hline \multirow{2}{*}{ Plenas } & Diálogo reportado da fala \\
\cline { 2 - 2 } Retóricas & $\begin{array}{l}\text { Não aguardam do interlocutor uma resposta } \\
\text { Elaborada com fins essencialmente argumentativos }\end{array}$ \\
\cline { 2 - 2 } Semirretóricas declarativas/objetivas & $\begin{array}{l}\text { Presença de pronome interrogativo com/sem preposição } \\
\text { Objetiva; direta; e aberta } \\
\text { Maior comprometimento do locutor }\end{array}$ \\
\cline { 2 - 2 } Semirretórica condicionais/subjetivas & $\begin{array}{l}\text { Presença de pronome interrogativo com/sem preposição } \\
\text { Subjetiva; indireta; e aberta/fechada } \\
\text { Menor comprometimento do locutor }\end{array}$ \\
\hline
\end{tabular}

As estratégias de interação permitem ao locutor/ escritor criar um efeito de maior proximidade com o seu interlocutor (neste caso o interlocutor/leitor). Em outras palavras, o locutor ao se valer das perguntas

\subsection{PRODUTIVIDADE DAS ESTRATÉGIAS DE SEQUENCIAÇ̃̃O DE INFORMAC̄̃̃ES NA ESCRITA}

Os itens linguísticos e, aí, então, depois, entre outros, conectam orações ou partes maiores de um discurso, desempenhando a função de elementos coesivos ou, também, se enquadram na função de sequenciadores de informação. A análise das estratégias de sequenciação de informações na escrita, toma como amostra as 80 redações da amostra Fala\&Escrita. As redações estão estratificadas socialmente quanto ao sexo, faixa etária e escolaridade, o que subsidia a análise do perfil do informante, pois o que se quer é testar se a escolha dos sequenciadores traz indícios de pertencimento regional, sexual, etário, entre outros. busca interagir com o leitor, ocasionando um efeito de proximidade mais afetiva e de subjetividade ao texto escrito, buscando envolvê-lo.

Foram identificadas cada uma das ocorrências dos tipos de sequenciador (então, e, aí e depois) na amostra, que foram cotejados às variáveis sociais - sexo e escolaridade - e linguísticas - função semântico-discursiva, tipo de discurso e nível de articulação discursiva e posteriormente submetidas à análise estatística do pacote GOLDVARB X (SANKOFF; TAGLIAMONTE; SMITH, 2005).

A análise quantitativa computou 205 ocorrências - 11 de então, 160 de e, 23 de aíe 11 de depois (figura 1). 
Figura 1 - Distribuição dos dados de sequenciadores de informação

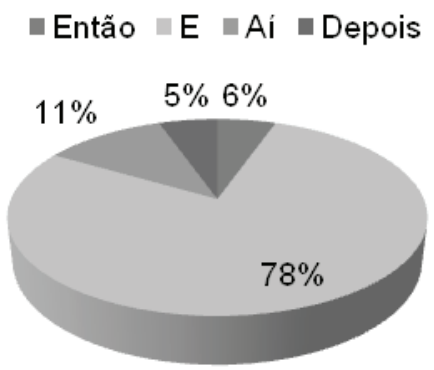

Os conectores aí, então, e, depois apresentam específicas funções semântico-discursivas, atuando como: sequenciador textual, sequenciador temporal, introdutor de efeito e finalizador.

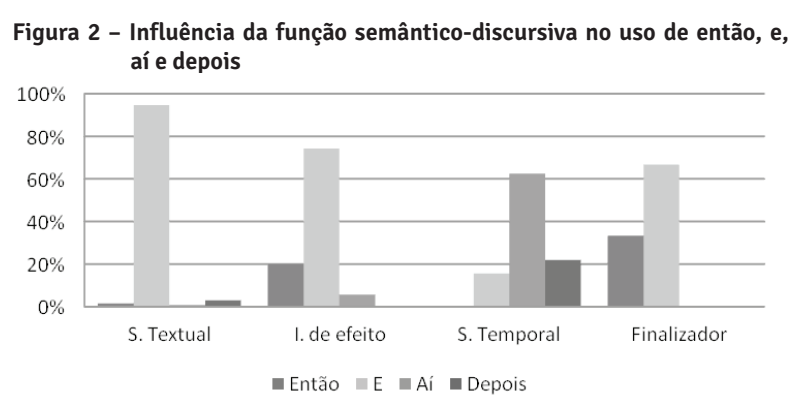

Constatou-se que a função de sequenciação textual favorece o maior uso do conector sequenciador $\boldsymbol{e}$, com a percentagem de $94,7 \%$, e inibe o uso do então $(1,5 \%)$, do aí $(0,8 \%)$ e do depois (3\%) (figura 2). Este resultado indica a tendência de o conector $\boldsymbol{e}$ assinalar a ordem sequencial das informações dada pelo locutor do texto. Entretanto, outras funções também condicionam favoravelmente o uso do conector e: introdutor de efeito $(74,3 \%)$ e finalizador $(66,7 \%)$. Já na função de sequenciação temporal, o conector $\mathbf{e}$ é inibido (15,6\%), sendo esta função mais associada ao uso do aí, com a $62,5 \%$, depois $(21,9 \%)$. Já o uso do aí é pouco associado às funções de sequenciador textual $(0,8 \%)$, introdutor de efeito $(5,7 \%)$ e finalizador $(0 \%)$.
A função de introdutor de efeito está mais associada ao uso do e $(74,3 \%)$ e do então (20\%), e desfavorece o uso do aí (5,7\%) e do depois (0\%). Esta função é responsável por indicar sequência cronológica na linha do tempo, interligando eventos, sendo o primeiro causa e o segundo consequência. A função de finalização favorece o uso dos conectores então (33,3\%) e e $(66,7 \%)$ e inibe os conectores aí e depois.

Foram classificadas as redações da amostra como predominantemente narrativas, explanativas e opinativas. As redações que apresentavam características de mais de uma tipologia foram rotuladas como híbridas.

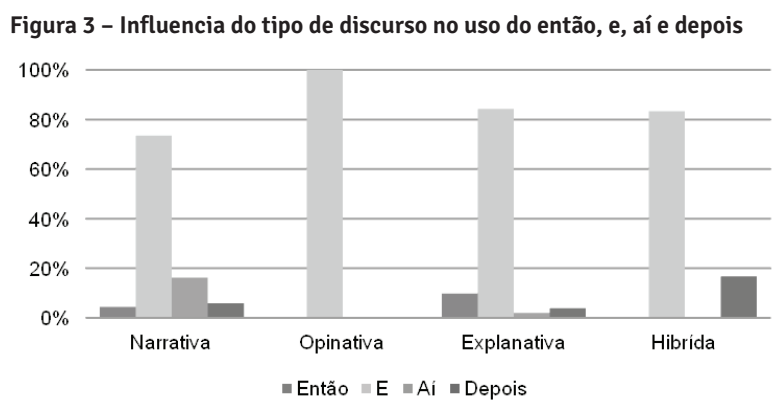

Os resultados apontam o favorecimento do uso de e e aí, respectivamente com $73,5 \%$ e $16,2 \%$, em narrativas, em oposição aos conectores então e depois (figura 3). 0 conecto aí é favorecido pela função semântico-discursiva sequenciação temporal, a qual está ligada à cronologia das informações na linha do tempo, e também a narrativa é caracterizada pela sequência cronológica. Dessa forma, o favorecimento de aí, neste tipo de texto, está ligado, também, à função semântico-discursiva que o conector desempenha.

0 tipo de texto dissertativo opinativo favorece o uso do conector e, e inibe o uso dos outros conectores, então, aí e depois. Como os textos dissertativos não tratam de um ser específico, como os textos narrativos, e não estão ligados à temporalidade, pode-se supor que a inibição do uso de então, aí e depois 
decorre da noção de temporalidade envolvida, já que esses conectores, menos o então, são condicionados pela função semântico-discursiva sequenciador temporal. Nos textos dissertativos explanativos, observou-se o predomínio do conector e, com $84,3 \%$, em contraposição aos conectores então (9,8\%), aí (2\%) e depois $(3,9 \%)$.

Os níveis de articulação referem-se ao grau de coerência textual estabelecida. A partir disso, foram considerados como níveis de articulação discursivos possíveis de serem marcados pelos conectores então, e, aí, depois os níveis intertópico, intratópico e inter-oracional.

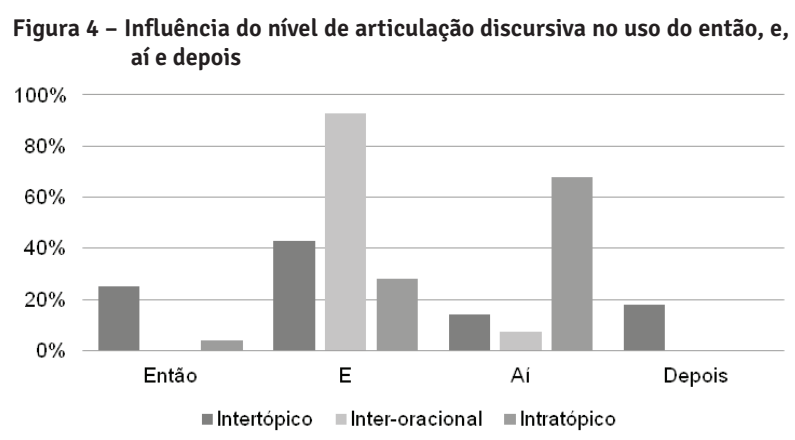

No nível intertópico todos os conectivos analisados são utilizados: então (25\%), e (42,9\%), aí (14,3\%) e depois (17,9\%) (figura 4). No nível inter-oracional, observouse o predomínio do uso do conector $\boldsymbol{e}$, com $92,8 \%$, o que pode, também, estar ligado à função semântico-discursiva de sequenciador textual, que marca a ordem sequencial das informações, e também o nível inter-oracional, que interliga orações, sendo um processo mais contínuo. No nível intratópico, os conectores $\boldsymbol{e}(28 \%)$ e aí (68\%) são mais produtivos. Os resultados referentes aos níveis discursivos evidenciam uma oposição entre o conector aí, condicionado pelos níveis mais descontínuos (intertópico e intratópico) e depois, então e e, condicionados pelo nível mais contínuo.
Quanto aos fatores sociais, os estudos sociolinguísticos apontam que homens e mulheres têm diferenças em seu falar. Apesar de observamos a escrita, podemos comprovar essa diferença: mulheres optaram pelos conectores e e então, formas canônicas e abonadas pela gramática normativa; já os homens fizeram mais usos do conector aí, considerado de estigma (figura 5).

Figura 5 - Influência do sexo no uso de então, e, aí e depois

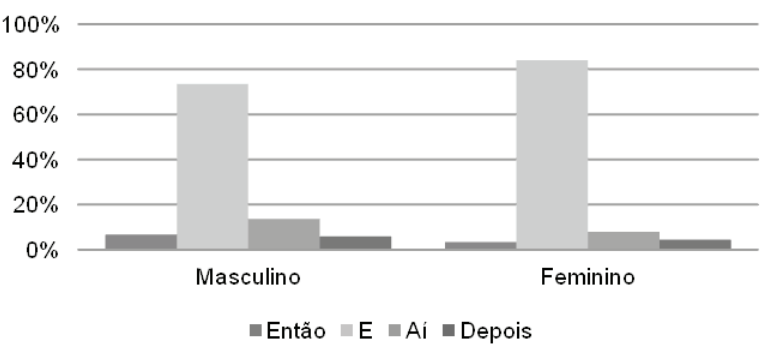

Homens tendem ao uso do conector e, com $73,5 \%$ e do aí com $13,7 \%$, forma tida como mais estigmatizada, o que comprova os estudos feitos por Fischer (1958, apud PAIVA, 2004), no qual ficou comprovado que os homens tendem a utilizar as formas menos prestigiadas. Já mulheres tendem ao uso do conector e, com de $84,1 \%$, polarizando o uso da forma tida como de prestígio.

Figura 6 - Influência da escolaridade no uso de então, e, aí e depois $100 \%$

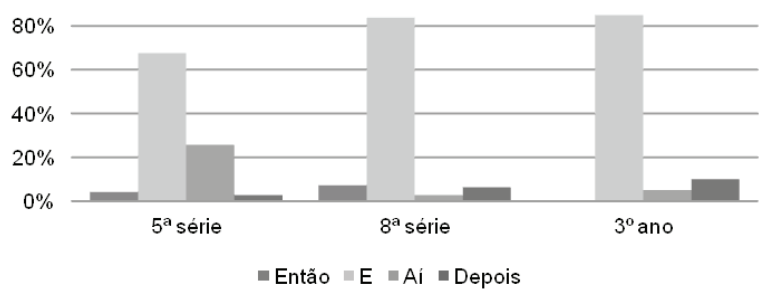

O prestígio e o estigma de formas na língua passam pela influência da escola; por isso, com o aumento do nível de escolaridade, espera-se que aumente o uso das formas de prestígio (figura 6). Com o aumento da 
escolaridade, ocorre redução do uso de conectores estigmatizados: no $6^{\circ}$ ano ( $5^{\mathrm{a}}$ série), predomina o uso dos conectores e (não estigmatizado), com 67,6\%, e aí, com percentual de $25,7 \%$, este tido como conector estigmatizado; já no $9^{\circ}$ ano ( $8^{a}$ série), percebeu-se um aumento do uso do e $(83,8 \%)$, e do então $(7,2 \%)$, já o uso do aí (2,7\%) decresce, o que evidencia a influência do fator escolaridade na escolha dos conectores, pois conectores como aí são refreados e tidos como vícios de linguagem pelos professores de Língua Portuguesa.

No terceiro ano do ensino médio, observa-se novamente o aumento do uso dos conectores $\boldsymbol{e}$, com
$85 \%$, e depois, com $10 \%$, e uma redução do uso do aí (5\%). A influência da escolaridade no uso dos conectores então, e, aí e depois aponta uma oposição entre conectores tidos como estigma social (aí), que predominam na escrita de alunos do $6^{\circ}$ ano, e aqueles de prestígio (e) tidos como não estigmatizados, com maior ocorrência na escrita de alunos do $3^{\circ}$ ano do ensino médio.

Os resultados sugerem uma tendência de distribuição para os conectores então, e, aí e depois, no quadro 2.

Quadro 2 - Traços característicos da ocorrência dos conectores na escrita

\begin{tabular}{|c|c|c|c|c|}
\hline & Então & $\mathbf{E}$ & Aí & Depois \\
\hline $\begin{array}{l}\text { Função semânti- } \\
\text { co-discursiva }\end{array}$ & $\begin{array}{l}\text { Introdutor de efeito } \\
\text { Finalizador }\end{array}$ & $\begin{array}{l}\text { Sequenciador textual } \\
\text { Introdutor de efeito }\end{array}$ & $\begin{array}{l}\text { Sequenciador } \\
\text { temporal }\end{array}$ & $\begin{array}{l}\text { Sequenciador } \\
\text { temporal }\end{array}$ \\
\hline Tipo de texto & Explanativo & $\begin{array}{l}\text { Narrativo } \\
\text { Opinativo } \\
\text { Explanativo } \\
\text { Híbrido }\end{array}$ & Narrativo & Híbrido \\
\hline $\begin{array}{l}\text { Nível de Articula- } \\
\text { ção Discursiva }\end{array}$ & Intertópico & $\begin{array}{l}\text { Intertópico } \\
\text { Inter-oracional }\end{array}$ & Intratópico & Intertópico \\
\hline Sexo & Masculino & Feminino & Masculino & Masculino \\
\hline Escolaridade & $9^{\circ}$ ano & $\begin{array}{l}9^{\circ} \text { ano } \\
3^{\circ} \text { ano EM }\end{array}$ & $6^{\circ}$ ano & $3^{\circ}$ ano EM \\
\hline
\end{tabular}

Tais resultados corroboram o processo de gramaticalização pelo qual passam os conectores então, e, aí e depois, tal como advoga Tavares (2003). Constatou-se, ainda, que a ocorrência do fenômeno sob análise está relacionada ao condicionamento de fatores linguísticos e sociais, o que evidencia um fenômeno de variação linguística, que precisa ser considerado nos programas de ensino de língua materna.

\subsection{ESTRATÉGIAS DE EVIDENCIALIDADE/MODALIZACÃ̃O}

Partiu-se da premissa que construções verbais podem passar a marcar a origem da fonte de informação, além do grau de adesão do falante em relação a seu enunciado e as estratégias de polidez que o locutor 
utiliza ao se comunicar, via gramaticalização. Identificou-se construções evidenciais/modalizadoras constituídas por verbos de opinião, crença ou saber, referentes às primeiras pessoas do singular e do plural.

A construção acho que, do ponto de vista formal, é constituída pelo verbo achar flexionado na $1^{a}$ pessoa do singular e do complementizador "que", introdutor de complemento oracional. Conforme descreve Freitag (2003), esta construção passa a atuar: i) como um marcador evidencial, porque atribui a origem da informação a uma fonte primária, tendo em vista a flexão de primeira pessoa do singular; e ii) também, a função de marcador de opinião, preparando o interlocutor para o que será dito posteriormente. Veja-se nos excertos (6) e (7), dados de fala da amostra Entrevistas Sociolinguísticas:

(6) eu acho... eu acho ela muito grande ela é boa essa escola a minha fessora é:: eu queria ficar com ela o ano todo ela é bem boa (se ita fpg 02).

(7) eu acho que:: as pessoas ... deveriam aceitas as outras como/ do jeito como elas como elas são (se ita fck 13).

Porém, em outros contextos, a construção, além de carregar a marca de evidencialidade (origem da informação: fonte primária), pode funcionar como marcador de dúvida (FREITAG, 2003), em contextos em que o falante não tem certeza ou não quer se comprometer com o que vai dizer, codificando a baixa adesão/não adesão do falante ao conteúdo proposicional, como ilustrado em (8):

(8) e aí agora com o pessoal do oitavo que é o pessoal que tá se formando... elas aglutinaram as pessoas juntaram as pessoas que... tavam no projeto da professora Josefa e o de Ana e que tem interesse... de tentar um mestrado... e aí a gente tem nesse grupo acho que na faixa de dez quinze pessoas... né? (se ita fp sq 02)

Em (8), não há relação de concordância entre o sujeito da oração "a gente" e a construção acho que, o que dá pistas de que esta funciona como um parenté- tico epistêmico, ocorrendo em posição livre na oração e sinalizando, também, uma instância mais avançada do processo de gramaticalização.

A construção acho que - e também outras construções oracionais de $1^{a}$ pessoa do singular como "eu acredito", "eu creio", “eu penso", por exemplo - assume a função de sinalizar a adesão do falante em relação ao conteúdo proposicional, dada sua fonte ser um verbo de traço cognitivo e na $1^{a}$ pessoa do singular. Entretanto, como visto, a depender da situação, a construção revela maior ou menor grau de adesão do falante em relação ao conteúdo proposicional, além de expressar a fonte da origem da informação: marcador de evidencialidade/opinião [maior adesão] e marcador de evidencialidade/dúvida [menor adesão].

Como as formas que acho (que) passa pelo processo de gramaticalização, possivelmente as construções verbais vamos dizer e digamos, também, são alvo desse processo, visto que todas elas possuem os mesmos traços funcionais, atuando como estratégia de polidez. É por meio da estratégia de polidez que o enunciador promove uma fuga, e não se compromete com as interpretações que o ouvinte venha a fazer, acontecendo assim a preservação de face. Dessa forma, ele evita as críticas a as confusões, que ocorreriam caso a pessoa de quem se fala, ou algum amigo ou parente soubesse. Com isso, o locutor tem permissão de pronunciar atos ameaçadores de face, sem responsabilizar-se. Essa possibilidade se confirma, além de outras coisas, devido ao uso das construções vamos dizer e digamos, como se vê em (9) e (10).

(9) Eu acho que poderia ter uma maior abordagem nela... assim do tipo (hes) incentivar mais os alunos porque hoje em dia aqui mesmo... vamos dizer... que não é todo mundo que é tão interessado com estudo (est) é eu não vou citar o meu exemplo porque ((risos)) mas aqui... percebe-se porque aqui o colégio eu vejo assim pessoas mais velhas... (se ita $\mathrm{mp} \mathrm{lq} \mathrm{03)}$

(10) aí às vezes ela ficava até puxando o meu saco né?

digamos assim entre aspas ((risos)) e aí quando eu saí do ensino fundamental e fui pro ensino ah quando 
eu sai do ensino fundamental não... quando eu saí da quarta série do ensino fundamental e fui pra quinta série do ensino fundamental. (se ita $\mathrm{mp}$ lq 03)

As construções sob análise são originadas das formas verbais de primeira pessoa do plural, e responsáveis por introduzir o conteúdo proposicional, isto é, opiniões, percepções, dúvidas, incertezas, (des) comprometimento e distanciamento por parte do falante em relação ao seu enunciado, e, por conta disso, po- dem estar se gramaticalizando como marcadores de evidencialidade/modalização.

Assim, as construções eu acho (que) e vamos dizer/digamos assumem a função semântico-discursiva de marcar (des)comprometimento e de distanciamento do falante em relação a seu enunciado, atuando como marcadores de opinião, de percepção, de dúvida, estratégias discursivas que não são abonadas pelas gramáticas normativas.

\section{CONSIDERACÕES FINAIS}

O desenvolvimento da investigação permitiu resultados mais acurados acerca da correlação entre usos linguísticos e contextos sociais, o que é essencial para a elaboração de materiais didáticos que contemplem a diversidade e a variedade linguística. Esperamos ter contribuído com reflexões e sugestões práticas para propiciar a articulação entre teoria e prática no ensino de língua materna, sugerida nos Parâmetros Curriculares Nacionais (BRASIL, 1998).

\section{REFERÊNCIAS}

BRASIL. Secretaria de Educação Fundamental. Parâmetros Curriculares Nacionais: terceiro e quarto ciclos: língua portuguesa. Brasília: Secretaria de Educação Fundamental, 1998.

BYBEE, Joan; PERKINGS, Revere; PAGLIUCA, William. The evolution of grammar: tense, aspect, and modality in the language of the world. Chicago: The University of Chicago Press, 1994.

FREITAG, Raquel Meister Ko. 0 papel da frequência de uso na gramaticalização de acho (que) e parece (que) marcadores de dúvida na fala de Florianópolis. Veredas, v. 7, n. 1, p. 113-132, 2003.

FREITAG, Raquel Meister Ko. Uma proposta de abordagem evolutiva para a mudança linguística. Gragoatá, v.25, p.131-148, 2008.

FURTADO DA CUNHA, M. Angélica. Corpus Discurso \& Gramática: a língua falada e escrita na cidade de Natal. Natal: EDUFRN, 2000.

GIVÓN, Talmy. Functionalism and grammar. Amsterdam/Philadelphia: John Benjamins Publishing, 1995. 
HEINE, Bernd; CLAUDI, Ulrike; HÜNNEMEYER, Friederike. Grammaticalization: a conceptual framework. Chicago: The University of Chicago Press, 1991.

HOPPER, Paul; TRAUGOTT, Elizabeth. Grammaticalization. Cambridge: Cambridge University Press, 1993.

KOCH, Ingedore Villaça. 0 texto e a construção dos sentidos. São Paulo: Contexto, 2008.

LABOV, William. Padrões sociolinguísticos. São Paulo: Parábola, 2008.

PAIVA, Maria da Conceição. A variável gênero/sexo. In: MOLLICA, Maria Cecília;

BRAGA, Maria Luiza (orgs.). Introdução à Sociolinguística: o tratamento da variação. São Paulo: Contexto, 2004.

SANKOFF, David; TAGLIAMONTE, Sally; SMITH, Edmond. Goldvarb X: A variable rule application for Macintosh and Windows. Department of Linguistics of University of Toronto, Department of Mathematics - University of Ottawa, 2005.

TAVARES, Maria Alice. A gramaticalização de E, AÍ, DAÍ, e ENTÃo: estratificação/variação e mudança no domínio funcional da sequenciarão retroativo-propulsora de informações - um estudo sociofuncionalista. Tese (Doutorado em Linguística) Programa de Pós-Graduação em Linguística da Universidade Federal de Santa Catarina, 2003.

URBANO, Hudinilson; FÁVERO, Leonor Lopes; ANDRADE, Maria Lúcia da Cunha Victório de Oliveira; AQUINO, Zilda Gaspar Oliveira de. Perguntas e respostas na conversação. In: Ataliba Teixeira Castilho (org.). Gramática do português falado. 3. Ed. Campinas: Editora da Unicamp, 2002. p. 75-97.

WEINREICH, Uriel; LABOV, William; HERZOG, Marvin I. Fundamentos empíricos para uma teoria da mudança linguística. São Paulo: Parábola, 2006. 

Vernáculas e do Programa de Pós-Graduação em Letras da Universidade Federal de Sergipe. E-mail: rkofreitag@uol.com.br

2 Graduada em Letras e mestranda do Programa de Pós-Graduação em Letras da Universidade Federal de Sergipe (bolsista FAPITEC). E-mail: andreialuzinete@hotmail.com

Graduada em Letras e mestranda do Programa de Pós-Graduação em Letras da Universidade Federal de Sergipe (bolsista CNPq). E-mail: ecciaalecia@hotmail.com

$4 \quad$ Graduada em Letras e mestranda do Programa de Pós-Graduação em Letras da Universidade Federal de Sergipe (bolsista CAPES). E-mail: jackelineufs_1004@hotmail.com

5 Graduanda em Letras Português, Universidade Federal de Sergipe/Campus Prof. Alberto Carvalho. E-mail: heloisacristinarenovato@ yahoo.com.br

6 Graduado em Letras Português, Universidade Federal de Sergipe/Campus Prof. Alberto Carvalho. E-mail: thiersletras@hotmail.com 